rence. With intermediate follow up the S pouch ileal neobladder incorporating the new antireflux technique appears to be effective in preventing reflux of urine without significantly increasing the incidence of obstruction. The clinical and functional results of $S$ pouch ileal neobladder appear to be accepted. Despite these encouraging results prolonged follow up will be required to determine the durability and long term complications associated with orthotopic ileal neobladder.

\section{REFERENCES}

1. Hautmann RE: Urinary diversion: ileal conduit to neobladder. J Urol. 2003; 169: 834-42.

2. Denewer A: A low-pressure rectosigmoid pouch created by side-to-side anastomosis with a stapling technique and sigmoid colon intussusception as an antireflux procedure. Br J Urol. 1998; 81: 856-61.

Dr. Adel Denewer Department of Surgical Oncology Oncology Center, Mansoura University Mansoura, Egypt E-mail: adeldenewer@mans.edu.eg

\title{
Men Reporting Lasting Longer with Hyperforin
}

To the Editor,

Premature ejaculation (PE) is a common, embarrassing and significantly under treated medical condition that affects men and their partners. Dapoxetine, a new short lasting selective serotonin reuptake inhibitor (SSRI), has demonstrated clinical efficacy in clinical trials when used immediately before intercourse (1). However, Dapoxetine has not yet been approved by the regulatory agency in part because of concern of risk and benefit ration of a SSRI in this quality of life condition.

We became interested if Hypericum perforatum, a natural supplement that has demonstrated pharmacologically to inhibit serotonin reuptake and can be formulated to help men last longer during sexual intercourse. In a rat model of ejaculation duration, hyperforin extract from Hypericum perforatum can delay time to ejaculation $(2,3)$.

Ten male volunteers took the rapid release formulation of hyperforin (DeLithe Nutraceutical, In., Pittsburgh, PA) for 8 weeks and assessed their sexual intercourse duration and sexual satisfaction.

In 5 men with mean ejaculatory duration at baseline of less than 90 seconds (mean age 39 years old), 4 reported lasting longer - mean time to ejaculation before and after treatment, $58 \pm 12$ seconds to $131 \pm 23$ seconds, respectively $(\mathrm{p}<0.01)$. Equally interesting, the mean sexual intercourse duration increased from $266 \pm 39$ to $391 \pm 34 \mathrm{sec}-$ onds ( $\mathrm{p}=0.02$ ) after Hyperforin extract treatment in 3 of 5 men with ejaculation greater than 3 minutes at baseline (mean age 43 years old). No adverse effect on sexual function and no systemic side effects were reported.

Seven of 10 couples reported subjective global sexual satisfaction improvement for both the men and his partner after hyperforin. Five couples reported more frequent female orgasm. Rapid onset of action, ease of use and safety make hyperforin extract an option for men who wish to last longer (4). Prospective randomized studies are necessary to further evaluation the utility of hyperforin extract.

\section{REFERENCES}

1. Pryor JL, Althof SE, Steidle C, Rosen RC, Hellstrom WJ, Shabsigh R, at al.: Efficacy and tolerability of 
dapoxetine in treatment of premature ejaculation: an integrated analysis of two double-blind, randomized controlled trials. Lancet. 2006; 368: 929-37.

2. Treiber K, Singer A, Henke B, Muller WE: Hyperforin activates nonselective cation channels (NSCCs). Br J Pharmacol. 2005; 145: 75-83.

3. Thomas CA, Tyagi S, Yoshimura N, Chancellor MB, Tyagi P: Effect of hyperforin enriched extract on pro- ejaculatory effect of 8-OH-DPAT In anesthetized rats. Urology. 2007; 70: 813-6.

4. Cannon-Smith TW, Kaufman JH: Improved ejaculatory control and sexual satisfaction in pilot study of men taking hypericum perforatum extract. The Internet Journal of Nutrition and Wellness. 2007; 3: 2.

Dr. Dae Kyung Kim Department of Urology Eulji University Republic of Korea

Dr. Michael B Chancellor Department of Urology William Beaumont Hospital 438 Medical Office Building 3535 W. 13 Mile Road Royal Oak, Michigan, 48073, USA E-mail: chancellormb@gmail.com 